\title{
Psychological Factors Related to Fear of COVID-19 in the General Salvadoran Population
}

\author{
Marlon Elías Lobos-Rivera ${ }^{1}$ (D) , Edgardo René Chacón-Andrade ${ }^{1}$ (D), Mauricio Cervigni ${ }^{2,3,4}$ (D), Miguel Gallegos ${ }^{5,6,7}$ (D), \\ Pablo Martino ${ }^{2,3,4}$ (D) , Tomás Caycho-Rodríguez ${ }^{8^{*}}$ (D), Ignacio Barés ${ }^{2,9,10}$ (D), Manuel Calandra ${ }^{2,9,10}$ (D), \\ Angélica Nohemy Flores-Monterrosa ${ }^{1}$ (D) , Víctor Manuel Ventura-Hernández ${ }^{1}$ (D)
}

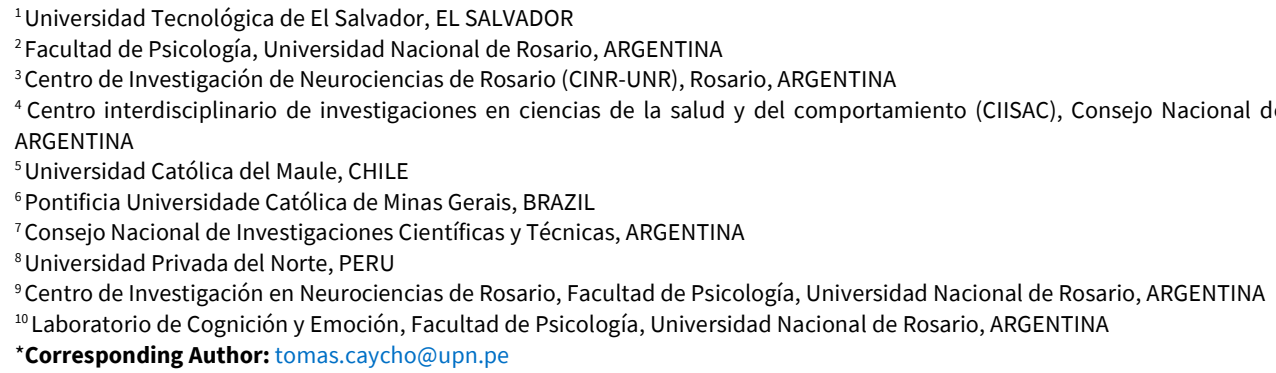

Citation: Lobos-Rivera ME, Chacón-Andrade ER, Cervigni M, Gallegos M, Martino P, Caycho-Rodríguez T, Barés I, Calandra M, Flores-Monterrosa AN, Ventura-Hernández VM. Psychological Factors Related to Fear of COVID-19 in the General Salvadoran Population. Electron J Gen Med. 2022;19(2):em351. https://doi.org/10.29333/ejgm/11550

\section{ARTICLE INFO}

Received: 19 May 2021

Accepted: 1 Nov. 2021

\begin{abstract}
Introduction: The objective of this article is to determine the psychological factors which are associated with the fear toward COVID-19 as experienced by the Salvadoran population in general.

Method: This study is exploratory, with a cross-sectional design. For data collection a digital survey in Google Forms was used. There was a non-probabilistic sample of 328 Salvadorans. The mean age in general was 27.90 years-old, with a standard deviation (SD) of 9.10; the mean age for men was 29.05 years-old $(S D=9.94)$, and the mean age for woman was 27.42 years-old $(S D=8.70)$.

Results: The results reveal the existence of small and medium correlations between anxiety, depression, instrumental support and positive social interaction with the variables of fear to COVID-19; the regression model predicted that the fear to COVID-19 depends on anxiety and affective support, predicting a $23 \%$ of fear to COVID19 , with medium effect.

Conclusion: This research suggests anxiety and affective support are explanation of the $23 \%$ of fear towards COVID-19 in Salvadoran population in general, findings provide useful information for future researches which perform a follow up or intervention in Salvadoran population in general.
\end{abstract}

Keywords: anxiety, depression, social support, fear, COVID-19, El Salvador

\section{INTRODUCTION}

In a globalized world, where travel is continuous and intercontinental communication is rapid, the announcement of the outbreak of a new virus in China emerged. On December $31^{\text {st }}, 2019$, The World Health Organization [1] office in China informed about the findings of a new type of coronavirus which show signs and clinic symptoms such as fever, breathing difficulty and, in some patients, thoracic X-rays showing internal pneumonic invasion in both lungs. National authorities informed that patients had been isolated and were receiving treatment in medical institutions in Wuhan [1]. According to the Pan American Health Organization [2] on January $30^{\text {th }}, 2020$, with more than 9,700 confirmed cases in China and 106 confirmed cases in other 19 countries, WHO's
Director-General declared that the outbreak was a Public Health Emergency of International Concern (PHEIC), and was accepting advice from the Emergency Committee of International Health Regulations (IHR). On February $11^{\text {th }}$, the WHO office named this disease COVID-19, a virus which was already expanding through the different continents. Between January $21^{\text {st }}$ and February $28^{\text {th }}, 33$ cases were confirmed among different countries of the American continent; the first ones being affected were the United States, Canada, Brazil and Mexico [2].

In light of this health emergency, Governments of different countries started taking some measures to try to retain the virus. El Salvador's Government through the executive decree $\mathrm{N}^{\circ} 12$ on March $21^{\text {st }}, 2020$, issued by Health Ministry, in which contains the extraordinary prevention and contention measures to decree national territory as a healthy controlled 
area with the goal to retain COVID-19 pandemic. A thirty days quarantine was declared, restricting transit and assembly freedom in the whole Salvadoran territory for health conservation. [3] Gradually, the quarantine was extended until June $16^{\text {th }}$ of the same year, announcing an organized reopening of economic activities [4]. On the other hand, at the beginning of this research on August $11^{\text {th }}, 2020$ [5] the virus active circulation on national territory was of 21,269 confirmed cases, 570 deceased and 9,875 recovered. At the closing of this research on April $20^{\text {th }}, 2021$ a total of 67,557 confirmed cases, 2,082 deceased and 63,787 recovered cases were reported. [6]. Evidencing an increase of 46,288 confirmed cases, 1,512 deceased and 53,912 recovered between August 2020 and April 2021.

These restriction measurements imposed onto the Salvadoran citizenship generated states of anxiety which were noted in actions that included compulsive purchasing, fear to social contact, different discrimination types and social interaction conflicts. In this sense, different researches demonstrate the psychological affections present in people. Researches made in El Salvador demonstrated the existence of psychological alterations, proving women present a higher emotional affectation and anxiety prevalence regarding COVID-19 infection [7-9]. On the other hand, Rajkumar [10] made a revision of tens of scientific publications about mental health before the COVID-19 pandemic in the Pubmed database. The author concludes that the most frequent psychological reactions shown in the majority of the published articles over the course of the pandemic are related to symptoms of depression, anxiety and stress. In the same manner, a systematic review reveals that scientific production is not enough yet to clarify the impact of SARS-CoV-2 asymptomatic and pre-symptomatic carriers in the disease's propagation [11]. On the other hand, Berberoglu and Dinler [12] demonstrated that communication plays a very important role in the creation of fear towards COVID-19, meanwhile, Demuyakor et al, [13] suggests that people who were exposed to information about COVID-19 vaccine in social media perceived that information as negative and developed higher levels of distrust towards COVID-19 vaccine.

The manifestation of emotional symptoms and their potential predictors in the Salvadoran population was sought through a cross-sectional, non-experimental and quantitative study, which aimed at finding the emotional symptoms experienced by people during the home quarantine for the COVID-19 pandemic in El Salvador. A proportional sampling constituted by 339 participants of both genders (62\% women and $38 \%$ men) was used, with an average age of 34.1 years-old $(S D=11.8)$. It was determined that $75 \%$ of the participants showed depression, anxiety and stress symptoms. Around a quarter of the whole sample reported that had experimented between medium and severe emotional symptoms during almost the three weeks of the state of exception and home quarantine; this proves the prevalence of emotional symptomatology. The research concludes that the emotional symptoms and variables of interest show high and strong associations among stress, anxiety and depression. The association between anxiety and fear of infection $(r=.33, p<$. $01)$ and the deterioration of relationships $(r=.32, p<.01)$, as well as the correlation among the latter one, the purchasing by panic $(r=.32, p<.01)$, and stress $(r=.40, p<.01)$ showed the findings being described. Panic purchasing is directly associated with the level of interest in the topic: fear of infection. The level of interest in the topic is related with the fear of infection and these two variables are the only ones which are associated with the approval of the precaution measurements implemented by the Government. (Respectively $r=.19$ y $r=.26, p<.01$ ). Finally, a multiple regression analysis was performed, through which it was demonstrated that anxiety is the only condition in which the main predictor is the fear of infection $(\beta=0.297, p=.001)$ [9].

Another descriptive research conducted in El Salvador, used a retrospective and cross-sectional design in order to investigate about anxiety symptoms because of COVID-19, as evidence of mental health affectation in Salvadoran university students; this study researched the reasons that determined the prevalence of anxiety symptoms due to the COVID-19 pandemic and the chronic disease affecting the relatives of Salvadoran university students. The study used a nonprobabilistic sampling, through the snowball sampling technique, with a sample of 1,440 university students, both male and female. The anxiety scale for COVID-19 (of own authorship) was also conducted. When contrasting the levels of severity in the category of anxiety due to COVID-19, and based on gender and age, the study found that there is an association between gender and anxiety due to COVID-19 $\left[X^{2}(3, N=1440)=\right.$ $30.48 ; p=.001 ; V=.15]$, and that women are the ones who present moderate, severe and very severe anxiety levels $(59,1 \%)$ [7]. International researches demonstrate that the fear to become infected of COVID-19 is higher in women, people between the ages of 20-29 years-old, 30-39 years-old, 50-59 years-old and older than 60 years-old, as well as those people who had of become infected of COVID-19 [14].

All previously mentioned findings evidence that stress, anxiety, depression and fear towards COVID-19 are affecting people, due to uncertainty that the pandemic itself had caused. For this reason, is relevant to investigate the fear towards COVID-19 and other psychological variables that possibly had been developed as a result of this phenomenon; which had generated changes in all people lifestyles in general.

Nowadays, saving lives and enforcing public health measurements, hygiene and sanitization are a priority. However, people's emotional needs require attention, otherwise, this can turn out in a silent pandemic, causing severe harm to people, society and economy. The COVID-19 pandemic is a high threat for both the physical and the mental health necessary of the well-being of entire societies [15]. The contributions presented on this document are intended to obtain empirical evidence about how COVID-19 had psychologically affected Salvadoran population in general, in order for these findings to be retaken by Governmental authorities of the country. As well as by institutions that care about a good mental health of Salvadoran people. In the same way, these findings are going to be important for academic and scientific communities and in Psychology field in El Salvador, since in such country there are just a few evidences of psychological researches of this matter.

For the above reasons, in this research, it is intended to establish 1) if psychological factors such as anxiety, depression and social support are related with fear towards COVID-19 in Salvadoran population in general. 2) Check if in this research exist statistic differences among the dimensions to measure, in function of socio-demographic variables. And 3) determine which psychological factors predict fear towards COVID-19. 


\section{METHOD}

\section{Participants}

This is an exploratory research with a cross-sectional design [16], using a non-probabilistic purposive sampling, evaluating 328 Salvadorans from different departments. A virtual survey through Google Forms was used as data collection technique. The mean age is 27.90 years-old with a Standard Deviation of 9.10; regarding gender, the mean age for men is 29.05 years-old with a standard deviation of 9.94 , and the mean age for women is 27.42 years-old with a Standard Deviation of 8.70 . Concerning gender, $98(29.9 \%)$ are men, and $230(70.1 \%)$ are women; age ranges are distributed in the following way: $121(36.9 \%)$ are between 17 and 23 years-old, $104(31.7 \%)$ are between 24 and 28 years-old, and $103(31.4 \%)$ are over 29 years-old; concerning the amount of hours people have been thinking (or exposed to information) about COVID19 , the findings show the following: 180 (54.9\%) think about the virus between 1 to 3 hours; 60 (18.3\%) between 3 to 5 hours; 40 (12.2\%) between 5 to 7 hours, and 48 (14.6\%) think about COVID-19 for more than 7 hours.

\section{Instruments}

General Anxiety Disorder (GAD-7) [17]. Is an instrument which consists of seven items carried out in a self-administered questionnaire using some of the DSM-IV criteria concerning the General Anxiety Disorder, GAD. These elements assist in identifying possible TAG cases as well as the degree of severity of some anxiety symptoms and the client is asked whether he or she has been able to identify their presence. The instrument is constituted by a Likert scale with answers totaling 4 points ( 0 = never, 1 = several days, 3 = half of the days and $4=$ almost daily). The reliability for this instrument is .92; in this particular research, the instrument showed an internal consistency index of .88 .

Patient Health Questionnaire (PHQ) [18]. It is an instrument used to evaluate depression. It consists of a self-administered survey used to evaluate frequent mental problems. Among them, the evaluation to detect the presence and severity of depression is highlighted. It consists of nine items which evaluate each one of the 9 criteria elements found in the DSMIV, in a scale from 0 (not at all) to 3 (almost every day) plus an item which evaluates the difficulty to perform jobs, house chores or getting along with others. This instrument been mainly validated and applied in primary care fields and it allows a first approach to depressive disorder patients. In addition, it proves useful, if used repetitively, to observe and optimize follow ups during treatment (in low treatment patients). The instrument has a reliability index of .89 using Cronbach's Alpha; for this research the respective analysis was replicated, obtaining the same index $(\alpha=.89)$.

MOS Questionnaire of Perceived Social Support [19, 20]. It is an instrument which measures the multidimensional nature of social support. The questionnaire contains a first question and two boxes in order to enter the answer in numbers. It is followed by nineteenth items that inquire about elements concerning the social support connections of the respondent, with a scale from (1) "Never" to five (5) "Always." It stands out and is characterized for being a short, comprehensible, selfadministered questionnaire which allows to investigate global support in four dimensions: emotional support (questions 3,4 $8,9,13,16,17,19$ ); instrumental support (questions 2, 5, 12, 15); positive social interaction (questions $7,11,14,18$ ); and affective support (questions $6,10,20$ ). In this research, the following reliability indexes were obtained: in emotional support, Cronbach's Alpha was .96; in instrumental support the index was .88; in positive social interaction it had an index of .93, and in affective support it had an index of .90 .

Fear of COVID-19 Scale (FCV-19S) [21]. This is an instrument which seeks to measure the fear towards COVID-19; the Spanish version [22] was used, it has 7 items, with 5 response options on a Likert-type scale ( 1 = totally disagree, 2 = disagree, $3=$ neither agree nor disagree, $4=$ agree, $5=$ totally agree). The FCV-19S is divided in two categories: emotional reactions to fear (items 1, 2, 4 and 5) with a Cronbach Alpha of .85, and somatic expressions of fear (items 3, 6 and 7) with a Cronbach Alpha of .83. International researches prove that the instrument has appropriate validity and reliability indexes [23-25]. For this research, the reliability indexes were replicated, thus obtaining the following ones: for emotional reactions to fear the index was .85 , and for somatic expressions of fear the index was 87 ; in addition, the total reliability index was obtained and this was 89 .

\section{Procedure}

Data recollection was made through an online survey during the second week on August, 2020 via Google Forms platform. The form link was shared via email and social media, before answering it, the importance of the research was explained. Guaranteeing confidentiality and anonymity of the answers based in Code of Ethics for Application of Psychology Profession in El Salvador guidelines [26].

\section{Data Analysis}

Data analysis was made through SPSS software version 21, to perform inferential analysis. For this purpose, on first instance Kolmogorov-Smirnov test for normality was applied to determine if data was normal or symmetrical. It was decided to use statistic techniques through non-parametric tests, which are the following ones: Mann-Whitney $U$ test, to determine if there are statistical differences between two exact groups in conjunction with Pearson coefficient ( $r$ ) to calculate the effect size using the suggested rates by Cohen [27], who indicates the rates between .10 and .30 are a small effect, the ones between .31 to .50 are medium effect, and the ones greater than .50 large effect. The second technique used is going to be the Kruskal-Wallis $\mathrm{H}$ test, which allows to check if there are statistical differences between 3 or more groups. To establish the effect size in this test, the Epsilon Coefficient Squared $\left(\varepsilon^{2}\right)$ [28] will be used. The effect sizes are the following: from .010 to .058 is a small effect, from .059 to .137 is a medium effect, and from .138 to .500 large effect. A Spearman correlation analysis $\left(r_{s}\right)$ will be performed to determine if there are correlations among the dimensions used in the study. Finally, a multiple regression model to predict fear of COVID-19 will be used through psychological variables, accompanied by the $F$ coefficient to estimate the effect size, where in which, from .02 to .14 is a small effect, from .15 to .34 medium effect, and over .35 is a large effect [27].

\section{RESULTS}

\section{Statistical Differences}

Implementing the Mann-Whitney $U$ test according to gender, statistical differences were found between men and 
Table 1. Mann-Whitney $U$ test as a function of gender

\begin{tabular}{|c|c|c|c|c|c|c|}
\hline Dimensions & Gender & $\mathbf{N}$ & Rank & $\mathbf{Z}$ & $\mathbf{p}$ & $r$ \\
\hline \multirow{3}{*}{ Anxiety } & Men & 98 & 141.94 & -2.82 & .005 & .16 \\
\hline & Women & 230 & 174.11 & & & \\
\hline & Total & 328 & & & & \\
\hline \multirow{3}{*}{ Depression } & Men & 98 & 142.76 & -2.72 & .007 & .15 \\
\hline & Women & 230 & 173.77 & & & \\
\hline & Total & 328 & & & & \\
\hline \multirow{3}{*}{ Emotional support } & Men & 98 & 163.58 & -0.12 & .908 & .01 \\
\hline & Women & 230 & 164.89 & & & \\
\hline & Total & 328 & & & & \\
\hline \multirow{3}{*}{ Instrumental support } & Men & 98 & 173.83 & -1.17 & .242 & .07 \\
\hline & Women & 230 & 160.53 & & & \\
\hline & Total & 328 & & & & \\
\hline \multirow{3}{*}{ Positive social interaction } & Men & 98 & 168.63 & -0.52 & .603 & .03 \\
\hline & Women & 230 & 162.74 & & & \\
\hline & Total & 328 & & & & \\
\hline \multirow{3}{*}{ Affective support } & Men & 98 & 164.89 & -0.05 & .961 & .00 \\
\hline & Women & 230 & 164.33 & & & \\
\hline & Total & 328 & & & & \\
\hline \multirow{3}{*}{ Emotional reactions of fear to COVID-19 } & Men & 98 & 135.77 & -3.59 & .001 & .20 \\
\hline & Women & 230 & 176.74 & & & \\
\hline & Total & 328 & & & & \\
\hline \multirow{3}{*}{ Somatic reactions of fear to COVID-19 } & Men & 98 & 157.14 & -0.95 & .344 & .05 \\
\hline & Women & 230 & 167.64 & & & \\
\hline & Total & 328 & & & & \\
\hline
\end{tabular}

Table 2. Application of Kruskal-Wallis $\mathrm{H}$ test as a function of age

\begin{tabular}{|c|c|c|c|c|c|c|}
\hline Dimensions & Age & $\mathbf{N}$ & Rank & $\mathbf{H}$ & $\mathbf{p}$ & $\varepsilon^{2}$ \\
\hline \multirow{4}{*}{ Anxiety } & 17 to 23 years-old & 121 & 177.75 & 7.79 & .020 & .024 \\
\hline & 24 to 28 years-old & 104 & 169.89 & & & \\
\hline & Over 29 years-old & 103 & 143.49 & & & \\
\hline & Total & 328 & & & & \\
\hline \multirow{4}{*}{ Depression } & 17 to 23 years-old & 121 & 184.70 & 12.13 & .002 & .037 \\
\hline & 24 to 28 years-old & 104 & 164.73 & & & \\
\hline & Over 29 years-old & 103 & 140.54 & & & \\
\hline & Total & 328 & & & & \\
\hline \multirow{4}{*}{ Emotional support } & 17 to 23 years-old & 121 & 164.09 & 0.34 & .845 & .001 \\
\hline & 24 to 28 years-old & 104 & 160.98 & & & \\
\hline & Over 29 years-old & 103 & 168.54 & & & \\
\hline & Total & 328 & & & & \\
\hline \multirow{4}{*}{ Instrumental support } & 17 to 23 years-old & 121 & 160.42 & 1.32 & .516 & .004 \\
\hline & 24 to 28 years-old & 104 & 160.50 & & & \\
\hline & Over 29 years-old & 103 & 173.34 & & & \\
\hline & Total & 328 & & & & \\
\hline \multirow{4}{*}{ Positive social interaction } & 17 to 23 years-old & 121 & 159.50 & 0.62 & .733 & .002 \\
\hline & 24 to 28 years-old & 104 & 165.63 & & & \\
\hline & Over 29 years-old & 103 & 169.24 & & & \\
\hline & Total & 328 & & & & \\
\hline \multirow{4}{*}{ Affective support } & 17 to 23 years-old & 121 & 161.44 & 0.39 & .825 & .001 \\
\hline & 24 to 28 years-old & 104 & 163.60 & & & \\
\hline & Over 29 years-old & 103 & 169.00 & & & \\
\hline & Total & 328 & & & & \\
\hline \multirow{4}{*}{ Emotional reactions of fear to COVID-19 } & 17 to 23 years-old & 121 & 162.57 & 0.65 & .723 & .002 \\
\hline & 24 to 28 years-old & 104 & 170.56 & & & \\
\hline & Over 29 years-old & 103 & 160.65 & & & \\
\hline & Total & 328 & & & & \\
\hline \multirow{4}{*}{ Somatic reactions of fear to COVID-19 } & 17 to 23 years-old & 121 & 162.56 & 1.23 & .540 & .004 \\
\hline & 24 to 28 years-old & 104 & 172.44 & & & \\
\hline & Over 29 years-old & 103 & 158.76 & & & \\
\hline & Total & 328 & & & & \\
\hline
\end{tabular}

women in the dimensions of anxiety, depression and emotional reactions of fear to COVID-19, being women the most affected group with a small effect. To verify the foregoing information (See Table 1).
In relation to the Kruskal-Wallis $\mathrm{H}$ test as according to age, statistical differences were found in anxiety and depression dimensions, with people between 17 and 23 years-old being the most affected group, compared to those between 24-28 years-old, and older than 29 years-old, with a small effect. To verify the foregoing information (See Table 2). 
Table 3. Spearman correlation analysis

\begin{tabular}{|c|c|c|c|c|c|c|c|c|}
\hline Dimensions & 1 & 2 & 3 & 4 & 5 & 6 & 7 & 8 \\
\hline Anxiety (1) & - & & & & & & & \\
\hline Depression (2) & $.708^{\star \star}$ & - & & & & & & \\
\hline Emotional support (3) & $-.146^{\star \star}$ & $-.223^{\star \star}$ & - & & & & & \\
\hline Instrumental support (4) & $-.147^{\star \star}$ & $-.180^{\star \star}$ & $.736^{\star \star}$ & - & & & & \\
\hline Positive social interaction (5) & $-.189^{\star \star}$ & $-.297^{\star \star}$ & $.851^{\star \star}$ & $.688^{\star \star}$ & - & & & \\
\hline Affective support (6) & $-.170^{\star \star}$ & $-.278^{\star \star}$ & $.787^{\star \star}$ & $.697^{\star \star}$ & $.870^{\star \star}$ & - & & \\
\hline Emotional reactions of fear to COVID-19 (7) & $.451^{\star \star}$ & $.279^{\star *}$ & .074 & .039 & .073 & .102 & - & \\
\hline Somatic reactions of fear to COVID-19 (8) & $.443^{\star \star}$ & $.346^{* \star}$ & -.101 & $-.123^{\star}$ & $-.116^{\star}$ & -.108 & $.655^{\star \star}$ & - \\
\hline
\end{tabular}

Note: ${ }^{\star}=p<.050 ;{ }^{\star \star}=p<.010$

Table 4. Multiple step regression, predicting fear of COVID-19

\begin{tabular}{|c|c|c|c|c|c|c|c|c|c|}
\hline Models & $\mathbf{F}$ & $\mathbf{R 2}$ & $\Delta \mathrm{R} 2$ & B & Standard error & $\boldsymbol{\beta}$ & $\mathbf{p}$ & $1-\beta$ & $f$ \\
\hline Model 1 & \multirow{2}{*}{$89.16(\mathrm{df}=1.326)$} & .215 & .212 & & & & .001 & 1.00 & .27 \\
\hline Anxiety & & & & 0.69 & 0.07 & 0.46 & .001 & & \\
\hline Model 2 & \multirow{2}{*}{$49.53(\mathrm{df}=2.325)$} & .234 & .229 & & & & .001 & 1.00 & .31 \\
\hline Anxiety & & & & 0.72 & 0.07 & 0.48 & .001 & & \\
\hline Affective support & & & & 0.26 & 0.09 & 0.14 & .005 & & \\
\hline
\end{tabular}

\section{Correlation Analysis}

The Spearman correlation analysis shows the existence of correlations among the dimensions of the fear towards COVID19's Scale with the psychological variables: in Table 3, medium positive correlations were found among emotional reactions of fear to COVID-19, anxiety and depression, and medium positive correlations were found among somatic fear reactions to COVID-19, anxiety and depression. And small negative correlations among somatic fear reactions to COVID-19, instrumental support and positive social interaction.

\section{Multiple Regression Model}

To test whether fear of COVID-19 is predicted by anxiety and emotional support, a multiple stepwise regression was carried out. The results in Table 4 detail that all the rates of significance, statistical power and effect size are adequate; and together, the variables predict $23 \%$ of the fear of COVID-19, with a medium effect.

\section{DISCUSSION}

The COVID-19 pandemic has been a threat which left diversity of affectations in different contexts. In the case of mental health, the pandemic, together with social isolation, will leave a diversity of psychological affectations in the Salvadoran population and in the world. The results of this research proves that in the Salvadoran population, in general, there are psychological effects that affect their daily lives. The study showed that the youngest group of women suffers more symptoms of anxiety and depression, and have more emotional reactions of fear to COVID-19; these findings are in line with the results obtained by Gutiérrez-Quintanilla et al [7], who demonstrated that women are the ones with more psychological affectation.

The correlation analysis indicated that the dimensions of fear to COVID-19 mostly correlates with anxiety and depression, indicating that the more symptoms of anxiety and depression the affected person has, the more fear reactions they will present. This discovery is similar to the findings obtained by Orellana and Orellana [9], who found out that anxiety is directly related to the fear of getting infected of COVID-19. The regression model reveals that fear to COVID-19 is directly predicted by anxiety and affective support by the individual in $23 \%$; In other words, the level of anxiety people present and if they receive little emotional support, generates more fear of catching COVID-19.

Fear to COVID-19 is a normal reaction for any individual; However, when other psychopathological symptoms are presented, they can affect their physical and psychological wellness, different researches reveal that anxiety and depression are the most frequent psychopathologies that have occurred during the course of the pandemic [10]. There are authors who consider that the fear to acquire the virus, named by them "Coronaphobia" is another spreading epidemic in people, which could generates symptoms of stress, anxiety and depression. Or if the person already suffered from these symptoms, can be intensified to the point that it could cause an imbalance in their daily activities (work, studies, living with peer groups, among others); for this reason, psychology professionals have a very important role nowadays. Since their mental health competences will be extremely useful for the care of possible psychologically affected patients during the pandemic.

In the research findings the following limitations should be taken in account: First of all, this research had a transversal design and had not previous information of mental health indicators of the participants before the COVD-19 pandemic outbreak. This does not allow to perform a casual interpretation of findings. Therefore, performing longitudinal studies will allow a better understanding of findings and possible predictors of mental health in the researched population though COVID-19 pandemic. Secondly, participants were selected through a non-probabilistic sampling: therefore, findings cannot be generalized towards all Salvadoran population. Future researches should consider stratified probabilistic sampling which allow to collect data from different population groups and diverse regions of the country. Thirdly, as it was mentioned before, information about presence of mental disorders before the pandemic was not collected. This does not allow to have accuracy if the reported symptoms were related with the pandemic or if preexisted. So, it is suggested for future researches, background information of mental disorders of participants be included. Lastly, to evaluate the different symptoms of mental health, self-report measurements were applied, which are considered less 
accurate than an evaluation performed by a professional clinic of psychiatrist. Is so suggested in future researches objective measurements be included.

In conclusion, this research suggests anxiety and affective support explain the $23 \%$ of fear towards COVID-19. Findings from this research provide useful information for future researches which perform a follow-up or interventions in Salvadoran population in general, since it allows to identify people under the risk of mental health issues.

Author contributions: All authors have sufficiently contributed to the study, and agreed with the results and conclusions.

Funding: No funding source is reported for this study.

Declaration of interest: No conflict of interest is declared by authors.

\section{REFERENCES}

1. World Health Organization. Novel coronavirus - China. WHO. 2020. Available at: https://bit.ly/2IHZW8H (Accessed: 28 April 2021).

2. Pan American Health Organization. Epidemiological Update: Novel coronavirus (COVID-19). PAHO. 2020. Available at: https://bit.ly/3nGMC3a (Accessed: 28 April 2021).

3. Decree $\mathrm{N}^{\circ} 12$. Extraordinary prevention and contention measures to decree national territory as a healthy controlled area with the goal to retain COVID-19 pandemic. El Salvador. March 21, 2020. Available at: https://covid19.gob.sv/wp-content/uploads/2020/04/ Decreto-Ejecutivo-No12.pdf

4. El Salvador's government. President Bukele announced an organized reopening of economic activities starting on June $16^{\text {th }}$. 2020. Available at: https://bit.ly/3eCyz25 (Accessed: 28 April 2021).

5. El Salvador's Heath Ministry. Epidemiological Bulletin Week 32 (from August $2^{\text {nd }}$ to August $8^{\text {th }}, 2020$ ). MINSAL. 2020. Available at: https://bit.ly/3xwqnTa (Accessed: 30 April 2021).

6. El Salvador's Heath Ministry. Epidemiological Bulletin Week 15 (from April $11^{\text {th }}$ to April $17^{\text {th }}, 2021$ ). MINSAL. 2021. Available at: https://bit.ly/2QJaOXD (Accessed: 30 April 2021).

7. Gutiérrez Quintanilla JR, Lobos Rivera ME, Chacón Andrade ER. Síntomas de ansiedad por la COVID-19, como evidencia de afectación de salud mental en universitarios salvadoreños. San Salvador. Universidad Tecnológica de El Salvador. 2020. 22 p. Available at: https://bit.ly/3hQIBIH

8. Chacón Andrade ER, Lobos Rivera ME, Cervigni M, Gallegos M, Martino P, Caycho Rodríguez, T, et al. Prevalencia de ansiedad, depresión y miedo a la COVID-19 en la población general salvadoreña. Entorno. 2020;(70):76-86. https://doi.org/10.5377/entorno.v0i70.10373

9. Orellana C, Orellana L. Predictores de síntomas emocionales durante la cuarentena domiciliar por pandemia de COVID-19 en El Salvador. Actualidades en Psicología. 2020;34(128):103-120. https://doi.org/10.15517 /ap.v34i128.41431

10. Rajkumar RP. COVID-19 and mental health: A review of the existing literature. Asian J Psychiatr. 2020;52:102066. https://doi.org/10.1016/j.ajp.2020.102066 PMid:32302935 PMCid:PMC7151415
11. Obi OC, Odoh DA. Transmission of Coronavirus (SARS-CoV2) by presymptomatic and asymptomatic COVID-19 carriers: A systematic review. European J Med Ed Te. 2021; 14(3):em2110. https://doi.org/10.30935/ejmets/11060

12. Berberoglu A, Dinler A. The mediator role of communication about COVID-19 on the relationship between exaggeration of media and generated fear: Case of North Cyprus. J Clin Exp Invest. 2021;12(1):em00759. https://doi.org/10.29333/jcei/9281

13. Demuyakor, J, Nyatuame, IN, Obiri, S. Unmasking COVID-19 vaccine "Infodemic" in the social media. Online J Commun Media Technol, 2021;11(4):e202119. https://doi.org/ 10.30935/ojcmt/11200

14. Mejia CR, Rodriguez-Alarcon JF, Vera-Gonzales JJ, PonceLopez VL, Chamorro-Espinoza SE, Quispe-Sancho A, et al. Fear Perception of the COVID-19 Pandemic in Peru. Electron J Gen Med. 2021;18(3):em285. https://doi.org/ 10.29333/ejgm/9764

15. Pan American Health Organization. COVID-19 Recommended interventions in Mental Health and Psychosocial Support (MHPSS) during the Pandemic, June 2020. Available at: https://bit.ly/35JFHQC (Accessed: 30 April 2021).

16. Montero I, León OG. A guide for naming research studies in psychology. Int J Clin Health Psychol. 2007;7(3):847-62. Available at: http://www.aepc.es/ijchp/GNEIP07_es.pdf

17. Spitzer RL, Kroenke K, Williams JB, Löwe B. A brief measure for assessing generalized anxiety disorder: the GAD-7. Arch Intern Med. 2006 May 22;166(10):1092-7. https://doi.org/ 10.1001/archinte.166.10.1092 PMid:16717171

18. Kroenke K, Spitzer RL, Williams JB. The PHQ-9: validity of a brief depression severity measure. J Gen Intern Med. 2001;16(9):606-13. https://doi.org/10.1046/j.1525-1497. 2001.016009606.x PMid:11556941 PMCid:PMC1495268

19. Sherbourne CD, Stewart AL. The MOS social support survey. Soc Sci Med. 1991;32(6):705-14. https://doi.org/10.1016/ 0277-9536(91)90150-B

20. Londoño NE, Rogers H, Castilla JF, Posada S, Ochoa N, Jaramillo MA, et al. Validation of the Colombian MOS social support survey. Int J Psychol Res, 2012;5(1):142-50. https://doi.org/10.21500/20112084.770

21. Ahorsu DK, Lin CY, Imani V, Saffari M, Griffiths MD, Pakpour $\mathrm{AH}$. The fear of COVID-19 scale: Development and initial validation. Int J Ment Health Addict. 2020 Mar 27:1-9. https://doi.org/10.1007/s11469-020-00270-8

22. Huarcaya Victoria J, Villarreal Zegarra D, Podestà A, LunaCuadros MA. (2020). Psychometric Properties of a Spanish Version of the Fear of COVID-19 Scale in General Population of Lima, Peru. Int J Ment Health Addiction. 2020. https://doi.org/10.1007/s11469-020-00354-5

PMid:32837434 PMCid:PMC7307940

23. Midorikawa H, Aiba M, Lebowitz A, Taguchi T, Shiratori Y, Ogawa T, Takahashi A, Takahashi S, Nemoto K, Arai T, Tachikawa H. Confirming validity of the fear of COVID-19 scale in Japanese with a nationwide large-scale sample. PloS one. 2021 Feb 10;16(2):e0246840. https://doi.org/ 10.1371/journal.pone.0246840 PMid:33566868 PMCid: PMC7875410

24. Lin CY, Hou WL, Mamun MA, Aparecido da Silva J, et al.. Fear of COVID-19 Scale (FCV-19S) across countries: Measurement invariance issues. Nursing open. 2021 Jul;8(4):1892-908. https://doi.org/10.1002/nop2.855 PMid:33745219 PMCid:PMC8186712 
25. Nazari N, Safitri S, Usak M, Arabmarkadeh A, Griffiths MD. Psychometric validation of the Indonesian version of the fear of COVID-19 scale: Personality traits predict the fear of COVID-19. Int J Ment Health Addict. 2021 Aug 23:1-7. https://doi.org/10.1007/s11469-021-00593-0

26. Code of Ethics for Application of Psychology Profession in El Salvador El Salvador. November 10, 2010.
27. Cohen, J. Statistical Power analysis for the behavioral sciences. 2nd edition. London. Routledge. 1988. 400 p.

28. Ventura León JL. Tamaño del efecto para Kruskal-Wallis: aportes al artículo de Domínguez-González et al. Inv Ed Med. 2019;8(30):135-6. Available at: http://riem.facmed. unam. $\mathrm{mx} /$ node/933 